\title{
Diagnosis of plantwide oscillations: A harmonics analysis approach
}

\author{
Nahid Sanzida ${ }^{1,}{ }^{*}$, M. A. A. Shoukat Choudhury ${ }^{2}$ \\ 1,2 Department of Chemical Engineering, Bangladesh University of Engineering \& Technology, \\ Dhaka, Bangladesh
}

Index Terms:

Plantwide Oscillations

Root Cause Diagnosis

Nonlinearity

Harmonics

Received: 15 July 2015

Accepted: 13 November2015

Published: 15 October 2015

\begin{abstract}
Highly complex and integrated modern chemical process plants are susceptible to disturbances propagate throughout the plant from one unit to other interconnected units and create plantwide oscillations. These persisting oscillations are originated due to various faults such as sensor faults, valve faults, process faults, and controller tuning faults. A fundamental frequency and its harmonics can characterize these types of nonlinear faults. This paper demonstrates a novel datadriven off-line time-domain method to identify the root cause of plantwide or unitwide disturbances to troubleshoot plantwide disturbances using harmonics analysis. The successful application of the proposed method has been demonstrated through simulated data.
\end{abstract}

(C) 2015 TAF Publishing. All rights reserved

\section{INTRODUCTION}

It is obvious that when an oscillation is generated in a particular part in a highly complex and integrated modern chemical process plants, it then propagates throughout the whole plant or a group of interconnected units. These oscillations are termed as plantwide or unitwide oscillation(s) which ultimately pose a large threat on product quality, running cost and profitability because production and throughput may have to back away from their optimum settings to accommodate process variability [1].

Thus, it is important for process control engineers to

\footnotetext{
* Corresponding author: Nahid Sanzida

E-mail: nahidsanzida@che.buet.ac.bd
}

detect and diagnose the causes of oscillations or disturbances in a chemical process operation as soon as possible [2], [3]. Over the last few years, some studies were carried out to detect plantwide oscillations [4], [5] and to group the similar oscillations together. For the detection of oscillations in process measurements and identify signals with common oscillatory behavior, the use of spectral principal component analysis (PCA) [6] or autocorrelation function (ACF) [7] is suggested. [8] have proposed a technique that takes into account the interaction between the control loops. [9] introduced a new index called power spectral correlation index (PSCI) which is the correlation between the power spectra of two different measurements.

They proposed the use of PSCMAP (Power spectral 
correlation map) to automatically re-arrange and group variables together, which oscillate at a common frequency. However, after the detection of plantwide oscillation, the next step is the diagnosis of its root-cause. Recently there appeared a few papers that described a few techniques to perform root-cause diagnosis of plant-wide oscillation [9], [10], [11], [12], [13]. [6] Proposed a new procedure based on the spectral envelope method for detection and diagnosis of common oscillation(s). This paper demonstrates a novel data driven off-line time domain method to troubleshoot plantwide disturbances using harmonic analysis.

\section{A. Oscillations and Harmonics}

It is observed that nonlinearity induced oscillatory signals generally contain a fundamental frequency and its harmonics. A very common cause for oscillation is the presence of nonlinearity such as a valve stiction which often results in square-like waves in the controlled variable [15]

Figure 1 demonstrates the time series data and corresponding power spectra for a sticky valve. The time trend is almost rectangular and the power spectra give peaks at the normalized frequency of $0.0078,0.024$ and 0.039. Here, 0.0078 is the fundamental frequency and 0.024 and 0.039 are the third and fifth harmonics respectively. According to Fourier series any signal can be represented as a summation of sinusoids. Therefore, any time series $y(\mathrm{t})$, where $\mathrm{t} \in \mathrm{R}$ can be represented as,

$$
y(t)=\sum_{i=0}^{\infty} A_{i} \cos \left(\lambda_{i} t+\phi_{i}\right)
$$

For a signal containing harmonics, Equation (1) takes the following form:

$$
\mathrm{y}(\mathrm{t})=\sum_{i=0}^{M} \mathrm{~A}_{\mathrm{i}} \cos \left(\mathrm{i} * \lambda \mathrm{t}+\phi_{\mathrm{i}}\right)+\varepsilon(\mathrm{t})
$$
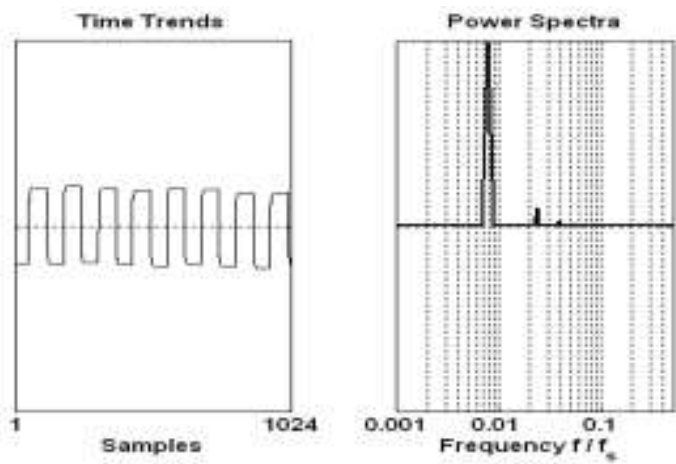

Fig. 1. Time series data and the power spectra for a sticky valve.

Where, $\lambda$ is the fundamental frequency. The general approach is to estimate the amplitudes, frequencies and phases for each term of Equation (2) and then examine the relationships among the frequencies to identify the presence of harmonics in the signal. [4] Suggested that it suffices to write the above expression only up to fifth harmonics for useful application of the analysis of chemical process data.

\section{B. Total Harmonic Content (THC)}

A new index called the Total Harmonic Content (THC) can be defined by the following expression of Equation 3,

$T H C=n \times W H M$

Where, $n$ is the number of harmonics found and WHM is the Weighted Harmonic Mean. WHM is defined as,

$$
W H M=\frac{\sum_{i=1}^{M} w_{i}}{\sum_{i=1}^{M} w_{i} / A_{i}}
$$

where $w_{i}$ is weights and is defined as $w_{i}=i / \sum_{\mathrm{i}=1}^{\mathrm{M}} i$. Due to the low-pass filtering effect of the chemical processes, the higher harmonics get filtered out gradually as the signal propagates away from the source or the root cause. Hence, more weights are given to the higher harmonics.

For plantwide oscillation(s) detection, the amplitudes, frequencies and phases of first five terms of equation (2) are estimated for time series data of each tag. Tags or variables having the same fundamental frequency and harmonics (if any) are identified. Weighted harmonic mean is calculated using amplitudes whose frequencies are in harmonics and multiplied by number of harmonics present. After calculating the THCs using equation (3), the variables are ranked according to the descending order of THC. The possibility of being the root cause increases with the increase of the value of THC.

\section{CASE STUDY}

\section{Simulation Example}

This simulation example involves a large, industrially relevant system of vinyl acetate monomer (VAc) manufacturing process. [14] Developed the Nonlinear Dynamic Model of this VAc process in MatLab which is freely available from the authors' website.

In the VAc process, there are 10 basic unit operations, which include a vaporizer, a catalytic plug flow reactor, a feed-effluent heat exchanger (FEHE), a separator, a gas 
compressor, an absorber, a carbon dioxide $\left(\mathrm{CO}_{2}\right)$ removal system, a gas removal system, a tank for the liquid recycle stream and an azeotropic distillation column with a decanter. There are seven chemical components in the VAc process. Ethylene $\left(\mathrm{C}_{2} \mathrm{H}_{4}\right)$, pure oxygen $\left(\mathrm{O}_{2}\right)$, and acetic acid (HAc) are converted into the vinyl acetate (VAc) product, and water $\left(\mathrm{H}_{2} \mathrm{O}\right)$ and carbon dioxide $\left(\mathrm{CO}_{2}\right)$ are byproducts. An inert, ethane $\left(\mathrm{C}_{2} \mathrm{H}_{6}\right)$, enters with the fresh $\mathrm{C}_{2} \mathrm{H}_{4}$ feed stream. For details, refer to [1]. Figure 2 shows a simplified schematic of the Vinyl Acetate Process with the locations of the manipulated variables.

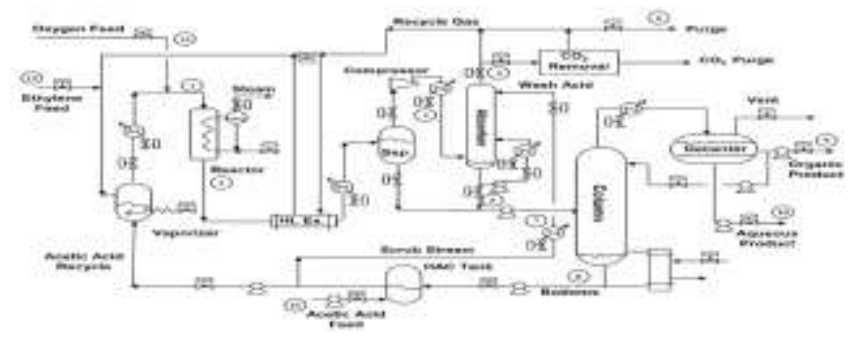

Fig. 2. VAc process flowsheet [1].

In order to create plantwide oscillations disturbance, valve stiction was introduced to control loops 9 and 14, independently. Valve stiction was introduced using Choudhury's stiction model [3]. To create limit cycle oscillations. The oscillation then propagate to the other control loops and eventually to the whole plant or some part of the plant.

In loop 9, the controlled variable is the separator temperature and the manipulated variable is the separator coolant valve corresponding to the cooling water flow rate for the separator jacket. After the process reached steady state, $5 \%$ stiction (where $\mathrm{S}=\mathrm{J}$ ) was introduced in the manipulated variable coolant valve. Simulation data set consisted of 2000 minutes of data with a sampling time of 15 seconds; therefore, each variable has 8000 observations. The last 1024 data points were used in this analysis in order to avoid transient behavior due to the sudden introduction of stiction.
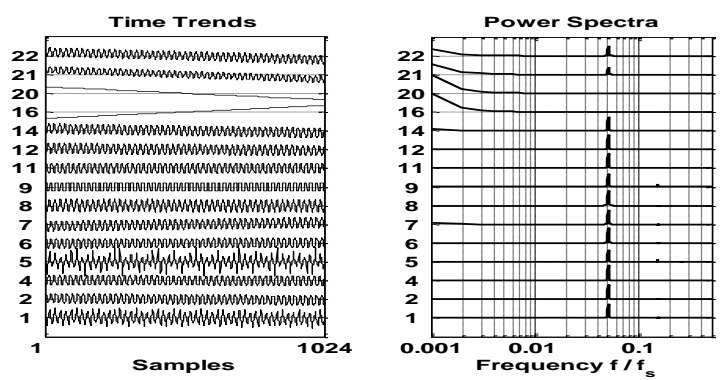

Fig. 3. Time trends and power spectra for the VAc process variables, applied stiction in loop 9 is $5 \%$.

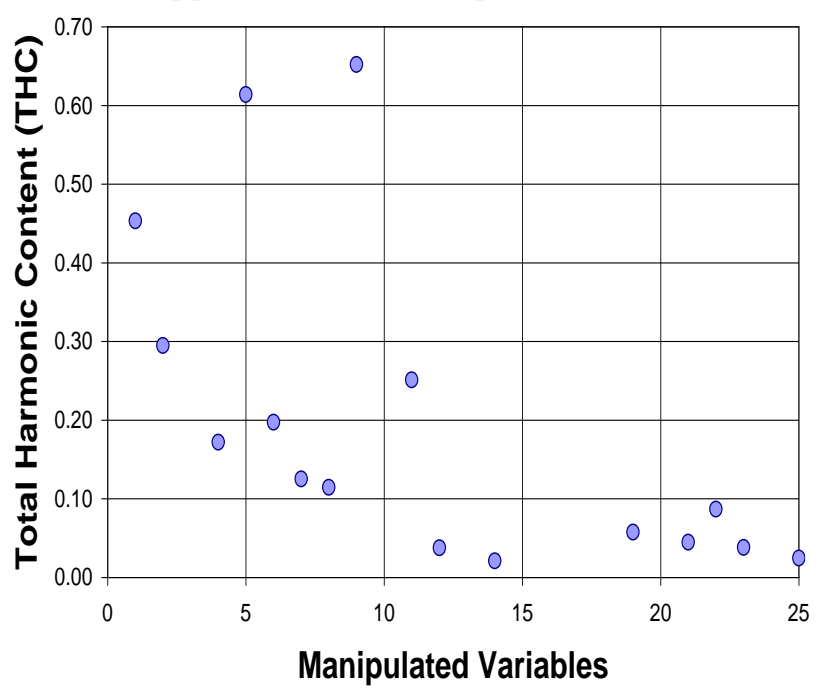

Fig. 4. THC values for the VAc process variables for $5 \%$ stiction applied in loop 9.

Figure 3 shows the time trends and power spectra which indicates that the variables $1,2,4,5,6,7,8,9,11,12,14$, 21 and 22 are oscillating together. The high density plot reveals that they are oscillating at a normalized frequency of 0.0505 .

Table 1 shows the harmonic analysis of the simulated data. The algorithm correctly identifies the presence of sinusoids in the signal. Five sinusoids are estimated for each signal. Total Harmonic Content (THC) was calculated for these variables. The maximum THC corresponds to tag 9 indicating the source or root-cause of the propagated oscillation because stiction was introduced in this variable during simulation. Figure 4 shows the calculated THC values against the variable or tag number.

\section{An Industrial Example-Application to a Refinery Data Set}

The proposed method was applied to a benchmark industrial data set for plantwide oscillations study appeared in the literature such as [9]-[10].

The data set, courtesy of a SE Asian Refinery, consists of 512 samples of 37 measurements sampled at $1 \mathrm{~min}$ interval. It comprises measurements of temperature, flow, pressure and level loop along with some composition measurements. Figure 5 depicts the time trends of the controller errors and the corresponding power spectra.

The calculated THC values are plotted against the tag number in Figure 6. The highest THC value corresponds to the tag no. 34 , which is the first candidate for the possible 
root-cause of this plantwide oscillation.
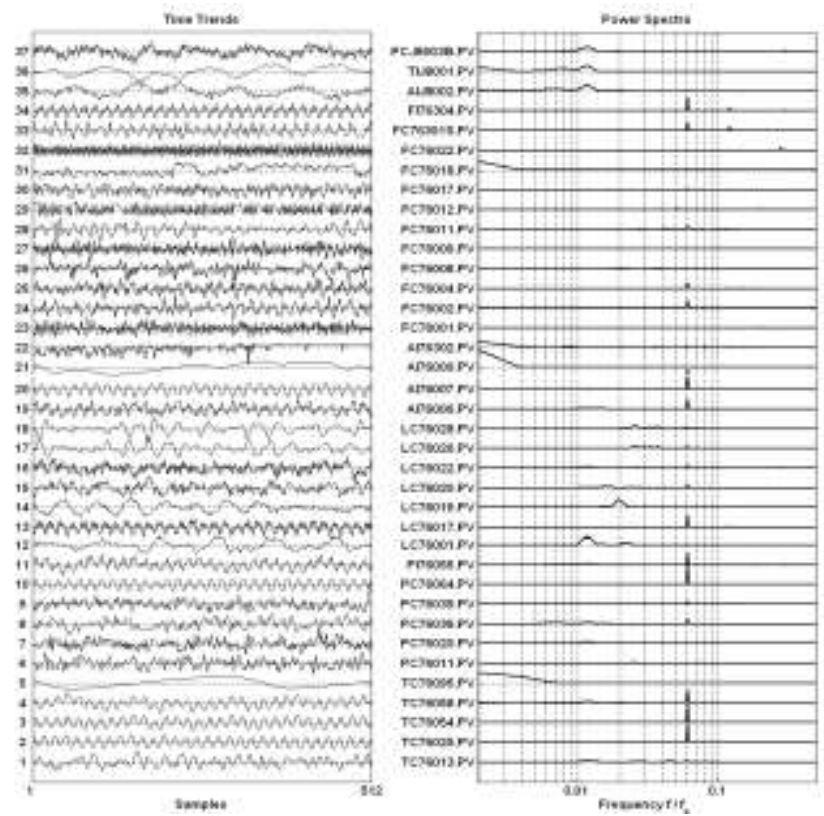

Fig. 5. Time trends and power spectra for the South-East Asia refinery data set.

From these figures, it can be found that the tags 2, 3, 4, $8,9,10,11,13,15,16,17,19,20,24,25,28,33$ and 34 are oscillating together with a common frequency of 0.0605 or 17 samples/cycle approximately. All data corresponding to the variables with the common frequency were first normalized so that they had zero mean and unit variance. Then the amplitudes, frequencies and phases for first five sinusoids were estimated and THCs were calculated for these variables.

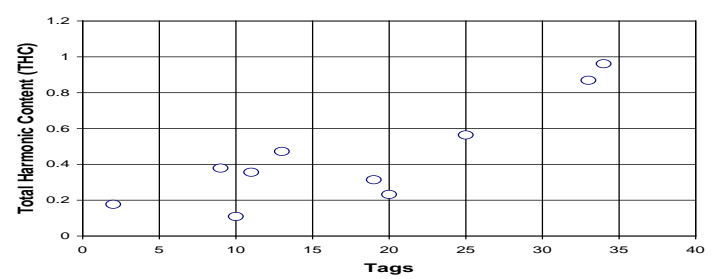

Fig. 6. Total harmonic contents (THC) results for SEA refinery data set.

In real plant investigation if this tag is not found to be the root cause, then the tag corresponding to next highest value of THC should be investigated. For this case, earlier studies [9], [10] and [11] found tag 34 as the root-cause. Therefore, the proposed THC index correctly detected the root-cause of this plantwide oscillation.

\section{CONCLUSION AND FUTURE WORK}

In this paper a new index called THC (Total Harmonic
Content) is introduced to troubleshoot plantwide oscillation(s). Through simulation and industrial data analysis case studies, it has been shown that THC is an effective tool for isolating the root cause of plantwide oscillation(s). The method can be automated to facilitate troubleshooting of plantwide oscillation.

\section{ACKNOWLEDGMENT}

We acknowledge Bangladesh University of Engineering and Technology (BUET), Dhaka, Bangladesh, for technical support and funding for this research.

\section{REFERENCES}

[1] R. Chen, K. Dave, T. McAvoy and M. Luyben, M. A nonlinear dynamic model of a vinyl acetate process. Indian Engineering Chemical Resources, vol. 42, no. 20, pp. 4478 - 4487. 2003. DOI: 10.1021/ie020859k

[2] M. A. S. Choudhury, M. A. Karim, S. Barua and N. Sanzida, "Root cause diagnosis of plantwide disturbance using harmonic analysis," in Preprints of ADCHEM 2009,( pp. 305- 309), Istanbul, Turkey.

[3] M. A. A. S. Choudhur, S. L. Shah and N. F. Thornhill, Diagnosis of Process Nonlinearities and Valve StictionData Driven Approaches. Springer Berlin Heidelberg, 2008.

[4] M. A. A. S. Choudhury, V. Kariwala, N. Thornhill, H. Douke, S. Shah, H. Takadac and J. Forbes, "Detection and diagnosis of plantwide oscillations," Canadian Journal of Chemical Engineering, vol. 85, no. 2, pp. 208-219, 2007. DOI: 10.1002 /cjce.5450850209

[5] A. Horch, V. Hegre, K. Hilmen, H. Melbø, L. Benabbas, S. Pistikopoulos, N. F. Thornhill and N. Bonavita. (n.d). Root cause-University and industry co-operation .[Online].Available https://library.e.abb.com/public/f622752d28bc2afe8 525704c006ec6fc/RootCause_HorchTornhillBonavita. pdf, date accessed July 25, 2015.

[6] H. Jiang, M. A. A. S. Choudhury and S. L. Shah, "Detection and diagnosis of plantwide oscillations from industrial data using the spectral envelope method," Journal of Process Control, vol. 17, no. 2, pp. 143-155, 2007. DOI: 10.1016/j.jprocont.2006.09.006

[7] M. A. Paulonis and J. W. Cox, "A practical approach for large-scale controller performance assessment, diagnosis and improvement," Journal of Process Control, vol. 13, no. 2, pp.155-68, 2003. DOI: 10.1016/S0959-1524(02)00018-5

[8] S. J. Qin, "Control performance monitoring-A review and assessment," Computers and Chemical 
Engineering, vol. 23, no. 2, pp. 173-186, 1998. DOI:10.1016/S0098-1354(98)00259-2

[9] A. Tangirala, S. Shah and N. Thornhill, "PSCMAP: A new tool for plantwide oscillation detection," Journal of Process Control, vol. 15, no. 8, pp. 931-941, 2005. DOI: $10.1016 /$ j.jprocont.2005.01.005

[10] A. Tangirala, J. Kanodia and S. L. Shah, "Non-negative matrix factorization for detection and diagnosis of plantwide oscillations," Industrial \& Engineering Chemistry Research, vol. 46, no. 3, pp. 80 -817, 2007. DOI: $10.1021 / \mathrm{ie} 0602299$

[11] N. F. Thornhill, S. L. Shah, B. Huang and A. Vishnubhotla, "Spectral principal component analysis of dynamic process data," Control Engineering Practice, vol. 10, pp. 833-846, 2002. DOI: 10.1016/S0967-0661(02)00035-7

[12] N. F. Thornhill, B. Huang and H. Zhang, "Detection of multiple oscillations in control loops," Journal of Process Control, vol. 13, no. 1, pp. 91-100, 2003. D0I: 10.1016/S0959-1524(02)00007-0

[13] C. Xia and J. Howell, "Loop status monitoring and fault localization," Journal of Process Control, vol. 13, no. 7, pp. 679-689, 2003. DOI: 10.1016/S09591524(02)00123-3

[14] X. Zang and J. Howell, "Isolating the root cause of propagated oscillations in process plants," International Journal of Adaptive Control and Signal Processing, vol. 19, no. 4, pp. 247-265, 2005. DOI: $10.1002 /$ acs. 860

[15] X. Zang and J. Howell, "Isolating the source of wholeplant oscillations through bi-amplitude ratio analysis," Control Engineering Practice, vol. 15, no. 1, pp. 69-76, 2007.

DOI: $10.1016 /$ j.conengprac.2006.03.006

\section{Appendix}

\begin{tabular}{|c|c|c|c|c|c|c|c|c|c|c|c|c|c|c|c|c|c|c|c|c|c|c|}
\hline & $\lambda_{1}$ & $\lambda_{2}$ & $\lambda_{3}$ & 2.4 & $\lambda_{5}$ & $A_{1}$ & $A_{2}$ & $A_{3}$ & $A_{4}$ & $\mathrm{~A}_{5}$ & $\phi_{1}$ & $b_{2}$ & $\beta_{3}$ & 9 & 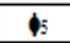 & $\lambda_{1} / \lambda_{1}$ & $\lambda_{2} / h_{1}$ & $\lambda_{3} / \lambda_{1}$ & $\lambda_{4} / \lambda_{1}$ & $\lambda: / \lambda_{1}$ & RESS & THC \\
\hline 1 & 0.317 & 0.951 & 1.585 & 2.219 & 2.853 & \begin{tabular}{|l}
1.339 \\
\end{tabular} & 0.309 & 0.169 & 0.114 & 0.083 & -0.69 & 2.812 & 0.856 & -0.91 & -2.63 & 1.000 & 3.000 & 5.000 & 7.000 & \begin{tabular}{|l|l|}
9.000 \\
\end{tabular} & 30.8 & 0.450 \\
\hline 2 & 0.317 & 0.951 & 1.585 & 2.219 & 2.853 & 1.383 & 0.266 & 0.101 & 0.051 & 0.029 & -2.44 & 1.366 & -0.50 & -2.24 & 2.397 & 1.000 & 3.000 & 5.000 & 7.000 & 9.000 & 1.8 & 0.293 \\
\hline 3 & 0.006 & 0.317 & 0.012 & 0.018 & 0.043 & 1.004 & 0.968 & 0.237 & 0.073 & 0.033 & -0.17 & 2.731 & 0.479 & 0.874 & 1.374 & 1.000 & 50.00 & 1.891 & 2.846 & 6.711 & 2.7 & \\
\hline 4 & 0.317 & 0.951 & 1.585 & .219 & 0.323 & 1.401 & 0.161 & 0.058 & 0.029 & 0.024 & 0.123 & -2.13 & 2.376 & 0.692 & -1.61 & 1.000 & 3.000 & 5.000 & 7.000 & \begin{tabular}{|l|l|}
1.019 \\
\end{tabular} & 1.2 & 0.136 \\
\hline 5 & 0.317 & 0.951 & 1.585 & 2.219 & 2.853 & 1.218 & 0.389 & 0.235 & 0.168 & 0.130 & -1.00 & 2.952 & 1.142 & -0.46 & -2.01 & 1.000 & 3.000 & 5.000 & 7.000 & \begin{tabular}{|l|l|}
9.000 \\
\end{tabular} & 135.4 & 0.603 \\
\hline 6 & 0.317 & 0.951 & 1.585 & 2.219 & 0.323 & 1.399 & 0.184 & 0.067 & 0.033 & 0.025 & -2.60 & 1.229 & -0.66 & -2.43 & 1.934 & 1.000 & 3.000 & 5.000 & 7.000 & 1.019 & 1.2 & 0.151 \\
\hline 7 & 0.317 & 0.951 & 1.585 & 2.219 & 0.323 & 1.401 & 0.181 & 0.057 & 0.025 & 0.026 & -2.37 & 0.709 & -1.38 & 2.947 & 2.175 & 1.000 & 3.000 & 5.000 & 7.000 & 1.019 & 0.9 & 0.140 \\
\hline 8 & 0.317 & 0.951 & 1.585 & 2.219 & 0.323 & 1.402 & 0.150 & 0.052 & 0.025 & 0.026 & -0.76 & -2.44 & 2.196 & 0.567 & -2.50 & 1.000 & 3.000 & 5.000 & 7.000 & 1.019 & 0.9 & 0.129 \\
\hline 9 & 0.317 & 0.951 & 1.585 & 2.220 & 2.854 & 1.272 & 0.423 & 0.252 & 0.178 & 0.137 & -2.33 & 2.400 & 0.848 & -0.69 & .22 & 1.000 & 3.000 & 5.000 & 7.000 & 9.000 & 45.0 & 0.649 \\
\hline 10 & 0.004 & 0.012 & 0.021 & 0.029 & 0.038 & 1.316 & 0.445 & 0.264 & 0.177 & 0.137 & -3.08 & 0.600 & -2.44 & 0.951 & -1.99 & 1.000 & 2.854 & 4.858 & 6.838 & 8.735 & 36.0 & \\
\hline 11 & 0.317 & 0.951 & 1.585 & 2.219 & 0.323 & 1.387 & 0.245 & 0.085 & 0.037 & 0.024 & -3.01 & 0.791 & -1.28 & 3.055 & 1.558 & 1.000 & 3.000 & 5.000 & 7.000 & 1.019 & 1.2 & 0.177 \\
\hline 12 & 0.317 & 0.951 & 0.323 & 0.311 & 1.585 & 1.412 & 0.067 & 0.026 & 0.025 & 0.009 & 0.613 & -2.90 & -1.14 & -0.98 & 1.160 & 1.000 & 3.000 & 1.019 & 0.982 & 5.000 & 0.3 & 033 \\
\hline 13 & 0.004 & 0.030 & 0.009 & 0.063 & 0.093 & 1.254 & 0.231 & 0.24 & 0.101 & 0.071 & 2.791 & 2.051 & -3.04 & -1.73 & 1.769 & 1.000 & 7.966 & 2.402 & 16.54 & 24.55 & 10.5 & \\
\hline 14 & 0.317 & 0.323 & 0.311 & 0.951 & 0.029 & 1.411 & 0.025 & 0.025 & 0.018 & 0.015 & 0.059 & -1.68 & -1.61 & -2.98 & -0.75 & 1.000 & 1.020 & 0.982 & 3.000 & 0.090 & 0.5 & 0.024 \\
\hline 15 & 0.004 & 0.025 & 0.009 & 0.078 & 0.052 & 1.241 & 0.236 & 0.238 & 0.086 & 0.127 & 2.823 & 2.336 & -2.96 & 2.133 & -1.10 & 1.000 & 6.474 & 2.399 & 20.46 & 13.55 & 14.8 & \\
\hline 16 & 0.006 & 0.012 & 0.017 & 0.029 & 0.023 & 1.404 & 0.346 & 0.134 & 0.091 & 0.093 & 3.104 & -3.09 & -3.03 & 2.895 & 3.065 & 1.000 & 1.902 & 2.719 & 4.547 & 3.630 & 3.0 & \\
\hline 17 & 0.007 & 0.014 & 0.024 & 0.030 & 0.042 & 1.245 & 0.516 & 0.299 & 0.203 & 0.140 & 2.886 & 0.549 & 2.713 & 1.675 & -3.12 & 1.000 & 1.971 & 3.407 & 4.190 & 5.909 & 31.6 & \\
\hline 18 & 0.007 & 0.011 & 0.004 & 0.020 & 0.025 & \begin{tabular}{|l}
0.927 \\
\end{tabular} & 0.382 & 0.798 & 0.181 & 0.082 & -2.71 & 2.195 & -2.50 & -2.48 & 2.587 & 1.000 & 1.581 & 0.611 & 2.840 & 3.556 & 10.7 & \\
\hline 19 & 0.317 & 0.951 & 0.323 & 0.311 & 1.585 & 1.409 & 0.085 & 0.026 & 0.024 & 0.022 & 2.335 & -1.29 & 0.610 & 0.687 & 2.766 & 1.000 & 3.000 & 1.019 & 0.982 & 5.000 & 0.4 & 0.064 \\
\hline 20 & 0.006 & 0.157 & 0.314 & 0.471 & 0.012 & 0.944 & 0.807 & 0.407 & 0.272 & 0.168 & -0.14 & 1.508 & 1.434 & 1.323 & 0.049 & 1.000 & 24.41 & 48.82 & 73.25 & 1.926 & 102.4 & \\
\hline 21 & 0.317 & 0.006 & 0.951 & 0.157 & 0.323 & 1.411 & 0.052 & 0.043 & 0.039 & 0.028 & -1.55 & -0.02 & -1.33 & -0.14 & 3.088 & 1.000 & 0.020 & 3.000 & 0.496 & 1.018 & 0.5 & \\
\hline 22 & 0.317 & 0.951 & 0.006 & 1.585 & 0.323 & 1.408 & 0.099 & 0.037 & 0.028 & 0.026 & -1.15 & -2.27 & 0.144 & 2.112 & -2.80 & 1.000 & 3.000 & 0.020 & 5.000 & 1.019 & 1.0 & \\
\hline 23 & 0.317 & 0.157 & 0.951 & 0.323 & 0.311 & 1.411 & 0.069 & 0.033 & 0.028 & 0.017 & -2.63 & -2.19 & 2.428 & 2.162 & 2.553 & 1.000 & 0.495 & 3.000 & 1.018 & 0.980 & 0.3 & \\
\hline 24 & 0.006 & 0.317 & 0.012 & 0.018 & 0.024 & 1.110 & 0.853 & 0.241 & 0.091 & 0.046 & -0.14 & -2.75 & 0.449 & 0.587 & 0.446 & 1.000 & 50.19 & 1.870 & 2.831 & 3.842 & 2.1 & \\
\hline 25 & 0.317 & 0.006 & 0.012 & 0.323 & 0.311 & 1.395 & 0.214 & 0.046 & 0.027 & 0.024 & 1.083 & 2.980 & -2.69 & -0.70 & -0.34 & 1.000 & 0.020 & 0.038 & 1.019 & 0.982 & 0.7 & \\
\hline 26 & 0.004 & 0.012 & 0.021 & 0.029 & 0.038 & 1.316 & 0.445 & 0.264 & 0.177 & 0.137 & 0.060 & -2.54 & 0.701 & -2.19 & 1.148 & 1.000 & 2.854 & 4.858 & 6.838 & 8.735 & 36.0 & \\
\hline
\end{tabular}

